Southern Illinois University Carbondale

OpenSIUC

Publications

Department of Plant Biology

$1-21-2015$

\title{
Uptake and accumulation of bulk and nanosized cerium oxide particles and ionic cerium by radish (Raphanus sativus L.).
}

Weilan Zhang

Southern Illinois University Carbondale

Stephen D. Ebbs

Southern Illinois University Carbondale, sebbs@plant.siu.edu

Craig Musante

The Connecticut Agricultural Experiment Station

Jason C. White

The Connecticut Agricultural Experiment Station

Cunmei Gao

Shanghai Ocean University

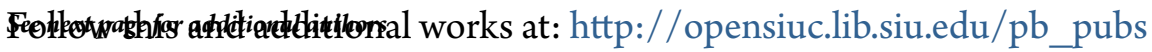

This document is the Accepted Manuscript version of a Published Work that appeared in final form in the Journal of agricultural and food chemistry, copyright (C) American Chemical Society after peer review and technical editing by the publisher. To access the final edited and published work see http://dx.doi.org/10.1021/jf5052442.

\section{Recommended Citation}

Zhang, Weilan, Ebbs, Stephen D., Musante, Craig, White, Jason C., Gao, Cunmei and Ma, Xingmao. "Uptake and accumulation of bulk and nanosized cerium oxide particles and ionic cerium by radish (Raphanus sativus L.).." Journal of agricultural and food chemistry 63, No. 2 (Jan 2015). doi:10.1021/jf5052442.

This Article is brought to you for free and open access by the Department of Plant Biology at OpenSIUC. It has been accepted for inclusion in Publications by an authorized administrator of OpenSIUC. For more information, please contact opensiuc@lib.siu.edu. 
Authors

Weilan Zhang, Stephen D. Ebbs, Craig Musante, Jason C. White, Cunmei Gao, and Xingmao Ma 


\section{Uptake and Accumulation of Bulk and Nano-sized Cerium Oxide Particles and}

\section{Ionic Cerium by Radish (Raphanus sativus L.)}

Weilan Zhang ${ }^{1}$, Stephen D. Ebbs ${ }^{2}$, Craig Musante ${ }^{3}$, Jason C. White ${ }^{3}$, Cunmei Gao ${ }^{1,4}$, Xingmao $\mathrm{Ma}^{1, *}$

${ }^{1}$ Department of Civil and Environmental Engineering, Southern Illinois University; Carbondale, IL, 62901

${ }^{2}$ Department of Plant Biology and Center for Ecology, Southern Illinois University, Carbondale, IL, 62901

${ }^{3}$ Department of Analytical Chemistry, The Connecticut Agricultural Experiment Station, 123 Huntington Street, New Haven, CT 06504, USA

${ }^{4}$ College of Marine Sciences, Shanghai Ocean University, Shanghai, 201306, China

*Corresponding author

Xingmao Ma

Department of Civil and Environmental Engineering

Southern Illinois University Carbondale

Carbondale, IL, USA, 62901

Ph: 618-453-7774

Fax: 618-453-3044

Email: ma@engr.siu.edu 


\begin{abstract}
The potential toxicity and accumulation of engineered nanomaterials (ENMs) in agricultural crops has become an area of great concern and intense investigation. Interestingly, while below ground vegetables are most likely to accumulate the highest concentrations of ENMs, little work has been done investigating the potential uptake and accumulation of ENMs for this plant group. The overall objective of this study was to evaluate how different forms of cerium (bulk cerium oxide, cerium oxide nanoparticles, and the cerium ion) affected the growth of radish (Raphanus sativus L.) and accumulation of cerium in the radish tissues. Ionic cerium $\left(\mathrm{Ce}^{3+}\right)$ had a negative effect on radish growth at $10 \mathrm{mg} \mathrm{CeCl}_{3} / \mathrm{L}$ while bulk cerium oxide $\left(\mathrm{CeO}_{2}\right)$ enhanced plant biomass at the same concentration. Treatment with $10 \mathrm{mg} / \mathrm{L}$ cerium oxide nanoparticles ( $\left.\mathrm{CeO}_{2} \mathrm{NPs}\right)$ had no significant effect on radish growth. Exposure to all forms of cerium resulted in the accumulation of this element in radish tissues, including the edible storage root. However, the accumulation patterns and their effect on plant growth and physiological processes varied with the characteristics of cerium. This study provides a critical frame of reference on the effects of $\mathrm{CeO}_{2}$ NPs vs. their bulk and ionic counterparts on radish growth.
\end{abstract}

\title{
Keywords
}

Cerium oxide, Nanomaterials, Nanoparticles, Radish, Phytotoxicity, Plant uptake 

are detected in wastewater streams $(4,5,6)$. As one of the most commonly employed

14 nanomaterials, cerium oxide nanoparticles ( $\left.\mathrm{CeO}_{2} \mathrm{NPs}\right)$ have attracted great attention. The

15 potential toxicity of $\mathrm{CeO}_{2} \mathrm{NPs}(6-40 \mathrm{~nm}$, unmodified) to bacteria, fish, and mammalian

16 cells has been reported $(7,8)$. Plants play a critical role in maintaining ecosystem health

17 and function and as a food source for humans. Plant uptake of ENMs represents an

18 important pathway for human exposure to these nanoparticles through food consumption

19 (9). Consequently, investigation of the uptake and accumulation of ENMs by agricultural

20 crops is not only warranted but also critical to food safety and human health. However,

21 there are only a small number of studies in the literature that have addressed the

22 interactions of $\mathrm{CeO}_{2}$ NPs with terrestrial plants (10-16). In one study, Wang et al. (10)

23 found that uncoated $\mathrm{CeO}_{2} \mathrm{NPs}(<25 \mathrm{~nm})$ at $0.1-10 \mathrm{mg} / \mathrm{L}$ had a slightly positive effect on

24 tomato (Solanum lycopersicum L.) growth and yield (e.g. increased production of tomato 
25 fruit at $10 \mathrm{mg} / \mathrm{L}$ ). However, cerium was reportedly transported from roots to shoots and

26 accumulated in edible tissues, although the chemical form of Ce was not determined.

27 These authors further investigated the trans-generational effect of $\mathrm{CeO}_{2} \mathrm{NPs}$ and found

28 that second generation seedlings grown with seeds from treated parental plants with 10

$29 \mathrm{mg} / \mathrm{L} \mathrm{CeO} 2 \mathrm{NPs}$ were significantly smaller and accumulated more cerium as compared to

30 seedlings generated from control plants (11). Ma et al. (12) studied how rare earth oxide

31 NPs affected root elongation and found that bare $\mathrm{CeO}_{2}$ NPs with an average diameter of

$327.2 \pm 0.7 \mathrm{~nm}$ had no effects on rape (Brassica napus L.), radish (Raphanus sativus L.),

33 wheat (Triticum aestivum L.), cabbage (Brassica oleracea L.), tomato (Lycopersicon

34 esculentum L.), and cucumber (Cucumis sativus L.) at 2,000 mg/L. Rico et al. (13)

35 demonstrated that exposing rice seedlings to bare $\mathrm{CeO}_{2}$ NPs with an average size of 231

$36 \pm 16 \mathrm{~nm}$ up to $500 \mathrm{mg} / \mathrm{L}$ for ten days caused no visible signs of toxicity. However, $\mathrm{CeO}_{2}$

37 NPs induced a concentration-dependent modification of the oxidative stress and

38 antioxidant defense system in the rice seedlings. Several studies have reported the uptake

39 and accumulation of $\mathrm{CeO}_{2} \mathrm{NPs}$ by agricultural crops. For instance, Zhang and colleagues

40 (14) showed that $7 \mathrm{~nm}$ and $25 \mathrm{~nm}$ bare $\mathrm{CeO}_{2} \mathrm{NPs}$ were detected in cucumber tissues but

41 the transport of cerium from roots to shoots was limited. Zhao et al. (15) investigated the

42 effects of bare and alginate coated $\mathrm{CeO}_{2} \mathrm{NPs}$ on corn plants and reported that surface

43 coating and soil organic matter could promote the translocation of cerium in higher plants.

44 A recent study demonstrated that intact $\mathrm{CeO}_{2} \mathrm{NPs}(7 \mathrm{~nm})$ were taken up by soybean roots

45 (16). In summary, $\mathrm{CeO}_{2}$ NPs can be taken up by plants and accumulated in plant tissues,

46 but the majority of the NPs appeared to remain in the root tissues, raising concerns on the

47 heightened accumulation of ENMs by root vegetables. 
Interestingly, even though the edible tissues of belowground vegetables often

49 have direct contact with soil-borne ENMs and present the highest potential for ENMs

50 accumulation in food crops, little attention has been paid to this important group of food

51 plants. In this study, radish (Raphanus sativus L.) was adopted as a model plant in that it

52 is a popular vegetable with high global consumption. In addition, radishes mature rapidly

53 in full sun and light, and can be harvested in 3-4 weeks, making it an ideal plant to study

54 the fate and impact of environmental chemicals on the development of belowground

55 vegetables. The objectives of this study were two-fold: 1) how does cerium in different

56 chemical forms (e.g. ionic cerium vs. cerium particles) and physical sizes affect the

57 growth of radish? (2) How extensively and differently will the radish tissues take up and

58 accumulate cerium in different forms and sizes? With these two objectives, we aimed to

59 fill some of the current knowledge gap on the possible differential accumulation of

60 cerium with different forms and particles sizes by plants. Even though detailed studies on

61 the cerium effect of essential physiological and biochemical processes are not the

62 concentration of this study, their interactions are important for mechanistic understanding

63 of the interactions of plants and nanoparticles and warrant further investigations.

64

65 Materials and Methods

66

67 Chemicals

68 Dispersions of $\mathrm{CeO}_{2}$ NPs (10 wt. \% in $\left.\mathrm{H}_{2} \mathrm{O}\right)$ and cerium chloride powder were

69 purchased from Sigma-Aldrich (St. Louis, $\mathrm{MO}$ ). The bulk powder of $\mathrm{CeO}_{2}$ was obtained

70 from Strem Chemicals, Inc. (Newburyport, MA). Hoagland solution (one-quarter

71 strength) was prepared by dissolving an appropriate amount of the modified Hoagland

72 basal salt mixture (Phytotechnology Laboratories, Lenexa, KS) with deionized water. The 
73 size and morphology of $\mathrm{CeO}_{2}$ NPs and the bulk suspensions were characterized by

74 transmission electron microscopy (TEM). The hydrodynamic size and zeta potential of

$75 \mathrm{CeO}_{2}$ NPs in quarter strength Hoagland solution were measured with a dynamic light

76 scattering instrument (Malvern Zetasizer Nano-ZS90, NY).

\section{Seed germination and growth conditions}

78 The radish seeds [Cherriette (F1)] were obtained from Johnny's Selected Seeds

79 (Winslow, ME). Seeds were surface sterilized with $1.25 \%$ sodium hypochlorite solution

80 for 10 minutes and then rinsed with deionized water three times. The sterilized seeds

81 were germinated on moist filter paper in a Petri dish for 7 days. Healthy young seedlings

82 with similar size (7.5 -8 cm in height from the root tip to the tip of cotyledons) and stage

83 of development were transferred to $50 \mathrm{~mL}$ polypropylene centrifuge tubes containing

84 quarter strength Hoagland solution and were incubated in a growth cart with a 16 hrs-

85 light/8 hrs-dark cycle $\left(28^{\circ} \mathrm{C}\right)$ to allow the seedlings to further develop. The growth cart

86 was equipped with four T5 fluorescent tubes, providing a light intensity of approximately

$87104 \mathrm{umol} \mathrm{m}^{-2} \cdot \mathrm{s}^{-1}$ of visible light $(400 \sim 700 \mathrm{~nm})$ at the height of plant leaves. After 7

88 days, the seedlings were transferred from the centrifuge tubes to $100 \mathrm{~mL}$ glass jars

89 containing $10 \mathrm{mg} / \mathrm{L}$ of bulk or nano-sized cerium oxide $\left(\mathrm{CeO}_{2}\right)$ or cerium chloride

90 ( $\left.\mathrm{CeCl}_{3}\right)$. Each jar had a floating lid made by Hareline $2 \mathrm{~mm}$ thin fly foam (Fishwest,

91 Sandy, UT) so that the plant roots were constantly submerged in the treatment solutions.

92 Due to the scarcity of information on the potential adsorption of cerium on foam surface,

93 it was assumed that the potential impact of foam on cerium bioavailability was

94 insignificant in this study. Four treatments were prepared, all in quarter strength

95 Hoagland solution: (1) control (no cerium treatment), (2) $10 \mathrm{mg} / \mathrm{L} \mathrm{CeO}_{2} \mathrm{NPs}$, (3) 10 
$96 \mathrm{mg} / \mathrm{L} \mathrm{CeO} 2$ bulk, and (4) $10 \mathrm{mg} / \mathrm{L} \mathrm{CeCl}$. The concentration of $10 \mathrm{mg} / \mathrm{L}$ was chosen

97 because this value is considered environmentally relevant (18) and our previous studies

98 also showed that $\mathrm{CeO}_{2} \mathrm{NPs}$ at this concentration slightly enhanced plant growth $(10,11)$.

99 Each treatment had 12 replicates. The solutions in the jars were replenished every other

100 day with the same treatment solution to compensate for evapotranspiration, with the

101 assumption that Ce would be taken up concurrently with water by plants. However, if

102 plants preferably take up water, it is possible that cerium would accumulate in the

103 growing solution. Plants were harvested 35 days after germination (i.e., 21 days after

104 treatment). Additionally, a separate set of radish plants were grown and treated exactly as

105 above. The harvested tissues from these plants were used to determine the distribution of

106 cerium across the fine root tips and storage roots microscopically (see below for details).

\section{Plant physiological responses}

108 For the first batch of plants, daily transpiration rate was recorded for each

109 seedling after they were transferred to $100 \mathrm{~mL}$ glass jars by measuring the water surface

110 drop before the solution replenishment. The cumulative transpiration of each treatment

111 was then calculated by summing the daily transpiration over the $21 \mathrm{~d}$ treatment period.

112 Relative chlorophyll content was measured with a SPAD 502 Plus Chlorophyll Meter

113 (Spectrum Technologies, Inc. Aurora, IL) one day prior to harvest and was expressed as a

114 percent of control. An OS1p chlorophyll fluorometer (Opti-sciences, Inc. Hudson, NH)

115 was used to measure the yield of quantum efficiency of PSII (light-adapted Y(II)) and the

116 photochemical efficiency of PSII (dark-adapted $\mathrm{F}_{\mathrm{V}} / \mathrm{F}_{\mathrm{M}}$ ) on the same day the relative

117 chlorophyll was measured. Five of the 12 replicates from each treatment were used in a

118 leakage test to assess root membrane integrity. The leakage test followed the published 
119 procedures with some modifications (19). Briefly, the entire fine root system was

120 submerged in $50 \mathrm{~mL}$ of deionized water and the initial conductivity $\mathrm{C}_{\mathrm{w}}$ was measured

121 immediately (Orion ROSS Ultra pH/ATC Triode Orion Star A325 Thermo Fisher

122 Scientific, Waltham, MA). The conductivity of the solution was measured again as $\mathrm{C}_{0}$

123 after 3 hours of incubation at room temperature. The entire fine roots were then

124 autoclaved at $121^{\circ} \mathrm{C}$ for 20 min with a Tuttnauer Brinkman 3850M autoclave to release

125 all electrolytes. The final conductivity $\mathrm{C}_{\mathrm{t}}$ was measured after the samples cooled to room

126 temperature. The percentage of electrolyte leakage was calculated as: $E L=\left(C_{0}-C_{w}\right) /\left(C_{t}-\right.$

$\left.127 \mathrm{C}_{\mathrm{w}}\right) \times 100$.

128 Uptake, accumulation and distribution of cerium

129 At harvest, radish plants were separated into fine roots, storage roots (the edible

130 radish bulb), and shoots. The tissues were then dried in an oven at $75^{\circ} \mathrm{C}$ for 7 days and

131 their dry weights determined. For each treatment, the 12 storage roots and 12 shoot

132 tissues were divided into to four groups respectively. The shoot and storage root tissues

133 in each group were then ground together into fine powders, from which $0.25 \mathrm{~g}$ of the

134 ground tissues were weighed and digested in $4 \mathrm{~mL}$ of $70 \%$ nitric acid and swirled to mix.

135 For the fine roots, the remaining seven replicates (five replicates used for the electrolyte

136 leakage test were excluded) were divided into three groups and each group contained

137 either two or three of the fine root systems. Due to the smaller biomass of the fine roots,

138 all ground tissues from each group were used for the digestion. The nitric acid digest was

139 heated at $95^{\circ} \mathrm{C}$ for 20 minutes and then $45^{\circ} \mathrm{C}$ for 4 minutes, and the cycle was repeated

1405 times until all the dry tissues were dissolved. Afterwards, $2 \mathrm{~mL}$ of hydrogen peroxide

141 was added to the mixture and heated using the same temperature cycle until the solution 
142 was clear. The digest solution was then analyzed by inductively coupled plasma - mass

143 spectrometry (ICP-MS) to obtain the concentration of cerium in each sample.

144 The radish roots used to determine the localization and distribution of cerium in

145 their fine roots and storage roots were harvested at day 21 after treatment. To obtain a

146 reference for the anatomy of the radish storage root, a cross section of the radish storage

147 root taken at the equator was cut with a razor blade and observed under a Kruss

148 MBL3000 light microscope (A.KRÜSS Optronic, Hamburg, Germany) (Supplementary

149 Figure 1). The radish fine root tips and sections of the storage roots from each treatment

150 were also examined using a Zeiss LSM 510 META confocal microscope. A laser

151 excitation wavelength of $543 \mathrm{~nm}$ was used and an emission filter band pass was set

152 between $530-590 \mathrm{~nm}$ to collect both the laser reflection and autofluorescence in this

153 region. To image the storage root, the root was first cut in half horizontally from the

154 thickest point and then a thin slice $(\sim 1 \mathrm{~mm})$ of the storage root was cut from the bottom

155 half of the storage root. That slice was then divided into four quarters and one of the

156 quarters was randomly selected to determine the radial distribution of cerium toward the

157 midpoint of the storage root. A schematic illustration of the slices preparation is shown in

158 Supplementary Figure 1. For each sample, a serial scanning along the z-axis of the

159 sample was conducted and the numbers of scanning planes varied from 8 to 11 . The

160 distance between two optical planes was approximately $10.2 \mu \mathrm{m}$.

\section{Data Analysis}

162 A one-way ANOVA was performed in this study for data analysis. The Duncan

163 test was conducted for post hoc comparisons. 


\section{Results}

\section{Characterization of $\mathrm{CeO}_{2} \mathrm{NPs}$ and the bulk}

167 Supplementary Figure 2 shows the TEM images of $\mathrm{CeO}_{2} \mathrm{NPs}$ and bulk $\mathrm{CeO}_{2}$ in

168 quarter strength Hoagland solution. The nanoparticles displayed variable shapes and

169 sizes. Individual nanoparticles possessed triangular, rectangular and other irregular

170 shapes. The images indicate that the average diameter of individual $\mathrm{CeO}_{2} \mathrm{NPs}_{\text {ranged }}$

171 from $10-30 \mathrm{~nm}$. The nanoparticles aggregated considerably in the Hoagland solution,

172 due to the high ionic strength. The hydrodynamic diameter of the nanoparticle aggregates

173 was $\sim 600 \mathrm{~nm}$ as measured by the DLS. The zeta potential of $\mathrm{CeO}_{2} \mathrm{NPs}$ in the Hoagland

174 solution was approximately $-11.9 \mathrm{mV}$, suggesting that the nanoparticles were not stable.

175 Bulk $\mathrm{CeO}_{2}$ were mostly at the micron scale but the sizes were not uniform. Particles at

176 the nanoscale were also detected in the bulk solutions. The sizes of bulk $\mathrm{CeO}_{2}$ ranged

177 approximately from $100 \mathrm{~nm}$ to $4,000 \mathrm{~nm}$.

\section{Plant physiological status}

179 The radish exposed to $\mathrm{CeO}_{2}$ bulk had the highest total dry biomass and was

180 significantly greater than all other treatments (Figure 1a). The biomass of the

181 nanoparticle treated plants was not significantly different from the control plants. The

182 plant biomass exposed to cerium ions was significantly lower than all other treatments.

183 When the plant tissues were examined separately, the bulk cerium treated radishes, which

184 had similar shoot biomasses as $\mathrm{CeO}_{2}$ NPs-treated radishes, had significantly higher dry

185 shoot biomass than control and cerium ions treatment (Figure 1b). The dry weight of

186 storage roots across the treatments exhibited similar patterns as the total dry biomass

187 (Figure 1c), but the dry biomass of fine roots did not differ significantly as a function of 
188 treatment (Figure 1d). In addition to the total biomass, the distribution of the biomass

189 between the root (fine + storage root) and shoot compartments was significantly different

190 in response to treatment. The shoot/root ratio of dry biomass of cerium ion treated radish

$191 \quad(1.34 \pm 0.11)$ was significantly higher $(\mathrm{p}<0.05)$ than all other treatments, which had

192 similar ratios (control: $1.00 \pm 0.10$; bulk $\mathrm{CeO}_{2}: 0.95 \pm 0.06$; $\mathrm{CeO}_{2} \mathrm{NPs}: 1.07 \pm 0.07$ ).

193 Visually, there was no apparent adverse effect of any of the cerium treatments on growth

194 and development of the radish plants except for the size differences (Figure 1e).

195 In addition to the root biomass, the fine root membrane integrity was significantly

196 affected by different forms of cerium. Figure 2 indicates that $10 \mathrm{mg} / \mathrm{L}$ of $\mathrm{CeO}_{2} \mathrm{NPs}$ and

197 ionic cerium resulted in significantly greater electrolyte leakage when compared to the

198 control roots. Leakage from bulk cerium treated roots was not significantly different from

199 control roots. The accumulative transpiration of radish for all treatments was comparable

200 until day 21, since then the accumulative transpiration of cerium ion treated radish

201 became significantly lower than other treatment groups (Supplementary Figure 3). The

202 relative chlorophyll content expressed in percentage is shown in Table 1. Although all

203 treated radishes had lower chlorophyll content, only the bulk $\mathrm{CeO}_{2}$ and $\mathrm{CeO}_{2} \mathrm{NPs}$ treated

204 leaves had significantly lower chlorophyll content compared to the controls. The average

205 quantum yield of photosystem II (Y(II)) and the Fv/Fm ratio for plants from different

206 treatments are also shown in Table 1. The results indicated that the Y(II) was unaffected

207 by the treatments. In contrast, only bulk $\mathrm{CeO}_{2}$ treated radishes displayed an $\mathrm{FV}_{\mathrm{V}} / \mathrm{F}_{\mathrm{M}}$ ratio

208 significantly lower value than the control. No significant differences were observed

209 between the other cerium treatments.

210 Cerium uptake and accumulation 
212 concentrations of this element in plant tissues. For the treated plants, the cerium

213 concentration and content were significantly higher in the fine roots than in other tissues

214 (Figure 3a-d). Among different treatments, the concentration of cerium in the storage root

215 was not significantly different between cerium treatments (Figure 3a). In the shoot

216 tissues, cerium ion treated radish had highest cerium concentration, followed by bulk

217 cerium and then $\mathrm{CeO}_{2} \mathrm{NPs}$ treated radish (Figure 3a). The fine roots of $\mathrm{CeO}_{2} \mathrm{NPs}$ treated

218 radish had significantly higher concentration of cerium than the bulk and ion treated

219 radish (Figure 3b). When the cerium content rather than the concentration in different

220 tissues was compared, cerium content in the storage roots of different treatments was still

221 similar. The shoot cerium content of bulk and ion treated radishes was not significantly

222 different but was markedly higher than nanoparticle treated radishes (Figure 3c). In the

223 fine roots, the cerium content demonstrated similar patterns as the cerium concentration

224 for different treatments (Figure 3d).

\section{Cerium localization and distribution in radish root and storage root}

226 For the fine root tips, the confocal microscopic images were captured both on the

227 surface and at different depths from the surface. The control had some weak signals from

228 either the cerium content in control tissues or from background excitation (Figure 4a). In

229 contrast, plant roots from treated plants all generated stronger signals (Figure 4b-f).

230 However, the signal patterns were noticeably different. On the bulk $\mathrm{CeO}_{2}$ treated root, the

231 signals were only detected from the mucilage surrounding the root tip in both surface and

232 deeper scanning images (Figure 4b,c). $\mathrm{CeO}_{2}$ NPs were detected on larger areas of the root

233 surface as well as the mucilage on the root tip of the nanoparticle treated plants (Figure 
234 4d). The signal was even more prominent in the deeper scanning planes (Figure 4e). For

235 cerium ion treated radish root, the signals were predominantly detected in the

236 surrounding areas. Neither the surface scan nor the deep scan detected significantly

237 stronger signals than the controls within the root itself (Figure 4f).

238 Figure 5 shows the confocal images of cut slices of radish storage roots. The

239 control storage root showed little signal (Figure 5a). In comparison, storage roots from

240 treated plants had strong signals. For bulk $\mathrm{CeO}_{2}$ treated radish, all signals came from the

241 pigmented periderm with a random pattern (Figure $5 b$ ). For $\mathrm{CeO}_{2} \mathrm{NPs}_{\mathrm{N}}$ treated radish,

242 stronger signals were observed in the pigmented periderm. In addition, the nanoparticles

243 appeared to penetrate further into the storage root (Figure 5c). Cerium was not only

244 detected in the periderm but also in the secondary vascular tissues in the storage root of

245 cerium ion treated radish (Figure 5d,e).

247 Discussion

248 Accompanied with the ever expanding applications of engineered nanomaterials

249 are the increasing concerns about their toxicity to humans and the environment. A major

250 question scientists are trying to ascertain is whether the reduction of micro-sized particles

251 to nano-sized particles will significantly increase their toxicity. Several previous studies

252 have shown that nanoparticles typically exhibit stronger effect on plants than their bulk

253 counterparts $(20,21)$. For example, following a 15-day hydroponic exposure, the biomass

254 of zucchini plant exposed to silver nanoparticles was $75 \%$ less than plants treated with

255 same concentrations of bulk silver powder (21). For $\mathrm{CeO}_{2}$ particles, it is well accepted

256 that the presence of highly mobile lattice oxygen on the surface will cause oxygen 
257 vacancy on the surface (22). With the decrease of nanoparticle size, the specific surface

258 area and consequently the density of the oxygen vacancy increase. The separation of

259 oxygen from the lattice structure generates electrons which can be used to reduce $\mathrm{Ce}^{4+}$ to

$260 \mathrm{Ce}^{3+}$. With increasing oxygen vacancy, the ratio of $\mathrm{Ce}^{3+} / \mathrm{Ce}^{4+}$ will increase on the surface

261 of nanoparticles (23). Because $\mathrm{Ce}^{3+}$ is about $14 \%$ larger than $\mathrm{Ce}^{4+}(22)$, the conversion of

$262 \mathrm{Ce}^{4+}$ to $\mathrm{Ce}^{3+}$ will strain the lattice structure and increase the reactivity and the superoxide

263 dismutase (SOD) mimetic activity of the $\mathrm{CeO}_{2}$ particles (24). Therefore, particle size is

264 an important consideration in the assessment of the environmental toxicity of $\mathrm{CeO}_{2}$.

265 Unfortunately, information on the size effect of $\mathrm{CeO}_{2}$ particles on plant development in

266 the literature is very limited.

267 Due to the potential dissolution of some metallic nanoparticles, another major

268 question actively investigated in the scientific community of nanotoxicology is the

269 comparative toxicity of nanoparticles and the ionic form of the particles. Because of the

270 general acceptance that $\mathrm{CeO}_{2} \mathrm{NPs}$ are stable in liquid solutions, ionic cerium was

271 generally not included in the treatment paradigms (13-16). However, the broad

272 applications of different forms and sizes of cerium require a comprehensive

273 understanding and comparison of their fate and phytotoxicity. Our investigation provides

274 an assessment of the differential fate and phytotoxicity of cerium in its ionic, nanoscale

275 and bulk particle forms. Several physiological parameters including the root membrane

276 integrity photosynthesis-related measurements, and biomass parameters were affected by

277 certain forms of cerium at the tested concentration.

278 While the specific mechanisms by which cerium compounds may compromise

279 membrane integrity are not known and may differ, all forms and sizes of cerium resulted 
280 in some damage to root membrane integrity as indicated by an increase in electrolyte

281 leakage. The effect was significant however only for the nanoparticle and ionic forms.

282 The changes in the integrity of root membrane could also alter the membrane potential

283 and potentially the function of the membrane (24). It has been reported that altered

284 plasma membrane integrity and potential is associated with changes in the ion fluxes into

285 plant roots (25). Whether this alteration of membrane integrity influenced the

286 concentration of any essential macronutrients or micronutrients in radish was not

287 examined but would be a reasonable question for future studies. For the bulk $\mathrm{CeO}_{2}$ and

$288 \mathrm{CeO}_{2} \mathrm{NPs}$, in addition to their impact on the membrane, physical adsorption on root

289 surface and blockage of nutrient uptake by plant roots may also occur. It is possible that

290 such impacts on the roots may have affected the uptake of elements such as magnesium

291 or iron, two nutrients associated with the synthesis of chlorophyll. A decrease in the

292 concentration of either of these essential nutrients might have contributed to the decrease

293 in relative chlorophyll content observed in some treatments. Other aspects of chlorophyll

294 synthesis or degradation could have been affected as well and a more detailed study will

295 be required to understand the extent or severity of effects of cerium on chlorophyll

296 metabolism. The significantly lower $\mathrm{F}_{\mathrm{V}} / \mathrm{F}_{\mathrm{M}}$ values observed for the bulk cerium treatment

297 as compared to the control plants suggested that photosynthetic electron transport

298 associated with photosystem II was stressed in those plants, but not for the other cerium

299 treatments. These results differ from a study with plantlets of Medicago arborea in

300 which nanoceria was found to have a more negative effect on the $\mathrm{F}_{V} / \mathrm{F}_{\mathrm{M}}$ ratio than the

301 same concentrations of bulk cerium (25). Other studies have shown that the influence of

302 cerium compounds on plant photochemistry differs depending on factors such as plant 
303 Mn status (26,) and the presence of salt stress (27). Definitive conclusions about the

304 comparative phytotoxicity of the cerium ion and nanoceria cannot be made without

305 further investigation. Even so, the overall effect of all treatments on the two

306 photosynthetic parameters measured were modest and perhaps not indicative of a

307 significant stress imposed on the plants, particularly given that there were no overt visible

308 effects observed for any treatments, including the ionic cerium and the $\mathrm{CeO}_{2} \mathrm{NPs}$

309 treatments. The only other indication of a negative effect of treatment with cerium was

310 the decrease in biomass observed for the cerium ion treatment.

311 The shoot/root ratio of radish was also affected by cerium, primarily through the

312 change of the biomass of the storage roots. Because the root thickening is a result of the

313 combined cell division and enlargement of secondary xylem and phloem cells which

314 depends on the activity of the vascular cambium (28), it is possible that the cerium of

315 different forms have different impacts on the activity of the vascular cambium. One could

316 speculate that the bulk $\mathrm{CeO}_{2}$ might have enhanced the activity of the vascular cambium

317 while ionic Ce inhibited it. Metabolically, according to the "sink capacity" theory, the

318 storage root represents a major reservoir for radish and sucrose transported within radish

319 is the main carbohydrate for the growth of sinks. As such, photosynthate distribution into

320 different tissues is heavily affected by the activity of sucrose synthase (SuSy) (29-32). If

321 future studies examined the expression of SuSy genes and/or measured the activity of this

322 enzyme in the radish hypocotyl in response to different forms of cerium, it might be

323 possible to ascertain whether the changes in the mass of the storage root in response to

324 bulk or ionic cerium treated radish plants were due to changes in sink strength. The

325 specific mechanisms by which these cerium compounds influence the biomass of radish 
326 storage roots has implications for the agricultural production of radish and related

327 vegetable species and are therefore worth further attention.

328 It should be pointed out that concentration of $\mathrm{CeCl}_{3}$ used in this study was very

329 low and the impact of chloride ion is not expected to be substantial. Parida and Das (33)

330 investigated plant salt tolerance and salinity effects on plant growth and the authors

331 reported that under $100 \mathrm{mM} \mathrm{NaCl}\left(3.55 \mathrm{~g} / \mathrm{L} \mathrm{Cl}^{-}\right)$, chloride demonstrated limited influence

332 on the osmotic adjustment of cell membrane. Scialabba and Melati (34) also reported that

333 sodium chloride up to a concentration of $0.1 \%$ positively affected radish growth. The $\mathrm{Cl}^{-}$

334 in the ionic cerium solution used in this study was significantly lower than those reported

335 values and was not expected to significantly contribute to the negative effect observed in

336 the ionic treatment group. Consequently, the negative effect observed in the ionic

337 treatment should be attributed to the ionic cerium. Another caveat about the results is that

$33810 \mathrm{mg} / \mathrm{L}$ was the concentration of the compounds of $\mathrm{CeO}_{2}$ and $\mathrm{CeCl}_{3}$, not the

339 concentration of cerium as an element. Due to the different molecular weight percentage

340 of cerium in $\mathrm{CeO}_{2}$ and $\mathrm{CeCl}_{3}$, the actual concentration of cerium as an element was 8.14

$341 \mathrm{mg} \mathrm{Ce} / \mathrm{L}$ in $\mathrm{CeO}_{2} \mathrm{NPs}$ and the bulk and was only $5.68 \mathrm{mg} \mathrm{Ce} / \mathrm{L}$ in the ionic form. Cerium

342 in $\mathrm{CeO}_{2}$ was $43.5 \%$ higher than in the ionic form. If the equivalent concentration of

343 cerium as an element was used, the ionic cerium may display an even stronger effect on

344 plant physiology.

345 In addition to the yield of edible storage root, the potential accumulation of

346 cerium was examined. Exposed plants had detectable cerium in all plant tissues,

347 including the edible storage roots and leaves even though the forms of cerium in these

348 tissues are unknown. However, the forms of cerium in plant tissues may affect both their 
349 toxicity and potential availability to humans and they deserve detailed investigation in

350 future studies. In current study, the significantly higher cerium detected in the shoot

351 tissues of exposed plants indicated that cerium translocation from roots to shoot had

352 occurred. The upward transport of bulk cerium to radish shoots was unexpected given the

353 size of the particles and the low dissolution rate of bulk $\mathrm{CeO}_{2}$. It is most likely that the

354 cerium content detected from the bulk treated shoot tissues was from the nanoscale

355 particles present in the bulk mixture (Supplementary Figure 2). The upward transport of

$356 \mathrm{CeO}_{2}$ NPs and ionic cerium from roots to shoots was expected and has been reported in

357 the literature $(10,14,35)$. Interestingly, however, when the cerium localization in the

358 storage root was investigated with the confocal microscope, signals of cerium in the

359 vascular tissues were only observed in cerium ion treatment, suggesting that active

360 transport may function as an important pathway of cerium accumulation only for ion

361 treated radishes. In contrast, signals from the $\mathrm{CeO}_{2} \mathrm{NPs}$ and bulk treated radish roots

362 were mainly located on the periderms. The results suggest that adsorption and diffusion

363 of particulate cerium along the radial direction might be a more important pathway for

$364 \mathrm{CeO}_{2}$ NPs and bulk accumulation in radish storage roots. The diffusion may possibly

365 occur from the lenticels on the periderm, but more precise techniques are needed to

366 confirm this assumption. From the food safety point of view, the cerium accumulation in

367 the edible storage root is more concerning and our results showed that while cerium

368 concentration and content were similar across the cerium treatment, the distribution of

369 cerium in the storage roots varied and consequently their availability to humans would

370 vary. For example, the majority of particulate cerium accumulated in the edible tissue

371 could be removed in the food preparation process while ionic cerium in the storage roots 
372 is more likely to be consumed by humans with the storage root.

373 In closing, our results suggested that $10 \mathrm{mg} / \mathrm{L}$ cerium as cerium oxide or cerium

374 chloride could affect the growth of radish and could accumulate in the edible storage root

375 and shoot tissues. However, the impact and accumulation patterns varied significantly by

376 the size and chemical form of cerium. Ionic cerium displayed the strongest impact on

377 radish root membrane integrity and growth, followed by $\mathrm{CeO}_{2} \mathrm{NPs}$ and then the bulk.

378 While cerium of different forms all accumulate in radish tissues, their accumulation

379 potential and distribution patterns varied greatly. As a result, potential exposure and risk

380 to human health through diet exposure to different sizes and forms of cerium may vary

381 and these differences should be considered when evaluating the food safety of cerium in

382 the environment.

383

384 Acknowledgement

385 The authors acknowledge the financial support of the USDA-AFRI (\#2012-67005-19585)

386 and USDA-AFRI (\#2011-67006-30181).

\section{Supporting Information Available}

389 The transmission electron microscopic images of bulk $\mathrm{CeO}_{2}$ and $\mathrm{CeO}_{2} \mathrm{NPs}$, the

390 accumulative transpiration of radish plants and the anatomy of radish storage root were

391 provided as supporting information. This information is available free of charge via the

392 Internet at http: //pubs.acs.org. 


\section{References}

396

397

398

399

400

401

402

403

404

405

406

407

408

409

410

411

412

413

414

415

416

417

418

419

420

421

422

423

424

425

426

427

428

429

430
(1) Tiede, K.; Hassellöv, M.; Breitbarth, E.; Chaudhry, Q.; Boxall, A., Considerations for Environmental Fate and Ecotoxicity Testing to Support Environmental Risk Assessments for Engineered Nanoparticles. J. Chromatogr. A. 2009, 1216(3), 503509.

(2) Nowack, B.; Bucheli, T. D., Occurrence, Behavior and Effects of Nanoparticles in the Environment. Environ. Pollut. 2007, 150(1), 5-22.

(3) Bystrzejewska-Piotrowska, G.; Golimowski, J.; Urban, P. L., Nanoparticles: Their Potential Toxicity, Waste and Environmental Management. Waste Manage. 2009, 29(9), 2587-2595.

(4) Brar, K.; Verma, M.; Tyagi, R. D.; Surampalli, R. Y. Engineered Nanoparticles in Wastewater and Wastewater Sludge - Evidence and Impacts. Waste Manage. 2010, 30(3), 504-520.

(5) Been, T. M.; Westerhoff, P. Nanoparticle Silver Released into Water from Commercially Available Sock Fabrics. Environ. Sci. Technol. 2008, 42(11), 41334139.

(6) Limbach, L. K.; Bereiter, R.; Müller, E.; Krebs, R.; Gälli, R.; Stark, W. J. Removal of Oxide Nanoparticles in a Model Wastewater Treatment Plant: Influence of Agglomeration and Surfactants on Clearing Efficiency. Environ. Sci. Technol. 2008, 42(15), 5828-5833.

(7) Pelletier, D. A.; Suresh, A. K.; Holton, G. A.; McKeown, C. K.; Wang, W.; Gu, B.; Mortensen, N. P.; Allison, D. P.; Joy, D. C.; Allison, M. R.; Brown, S. D.; Phelps, T. J.; Doktycz, M. J. Effects of Engineered Cerium Oxide Nanoparticles on Bacterial Growth and Viability. Appl. Environ. Microbiol. 2010, 76(24), 7981-7989.

(8) Rosenkranz, P.; Fernández-Cruz, M. L.; Conde, E.; Ramírez-Fernández, M. B.; Flores, J. C.; Fernández, M.; Navas, J. M. Effects of Cerium Oxide Nanoparticles to Fish and Mammalian Cell Lines: An Assessment of Cytotoxicity and Methodology. Toxicol. in Vitro. 2012, 26(6), 888-896.

(9) Zhu, H.; Han, J.; Xiao, J. Q.; Jin, Y. Uptake, Translocation, and Accumulation of Manufactured Iron Oxide Nanoparticles by Pumpkin Plants. J. Environ. Monit. 2008, 10(6), 713-717.

(10) Wang, Q.; Ma, X.; Zhang, W.; Pei, H.; Chen, Y. The Impact of Cerium Oxide Nanoparticles on Tomato (Solanum Lycopersicum L.) and Its Implications for Food Safety. Metallomics. 2012, 4(10), 1105-1112.

(11) Wang, Q.; Ebbs, S. D.; Chen, Y.; Ma, X. Trans-generational Impact of Cerium Oxide Nanoparticles on Tomato Plants. Metallomics. 2013, 5(6), 753-759. 
(12) Ma, Y.; Kuang, L.; He, X.; Bai, W.; Ding, Y.; Zhang Z.; Zhao, Y.; Chai, Z. Effects of Rare Earth Oxide Nanoparticles on Root Elongation of Plants. Chemosphere. 2010, 78(3), 273-279.

(13) Rico, C. M.; Hong J.; Morales, M. I.; Zhao, L.; Barrios, A. C.; Zhang, J. Y.; Peralta-Videa, J. R.; Gardea-Torresdey, J. L. Effect of Cerium Oxide Nanoparticles on Rice: A Study Involving the Antioxidant Defense System and In Vivo Fluorescence Imaging. Environ. Sci. Technol. 2013, 47(11), 5635-5642.

(14) Zhang, Z.; He, X.; Zhang, H.; Ma, Y.; Zhang, P.; Ding, Y; Zhao, Y. Uptake and Distribution of Ceria Nanoparticles in Cucumber Plants. Metallomics. 2011, 3(8), 816-822.

441 (15) Zhao, L.; Peralta-Videa, J. R.; Varela-Ramirez, A.; Castillo-Michel, H.; Li, C.; 442

(17) Boxall, A., Chaudhry, Q., Sinclair, C., Jones, A., Aitken, R., Jefferson, B., Watts, C. Current and Future Predicted Environmental Exposure to Engineered Nanoparticles. Central Science Laboratory, Department of the Environment and Rural Affairs, London, UK. 2007.

(18) Sanchez-Viveros, G.; Gonzalez-Mendoza, D.; Alarcon, A.; Ferrera-Cerrato, R. Copper Effects on Photosynthetic Activity and Membrane Leakage of Azolla Filiculoides and A. Caroliniana. Int. J. Agr. Biol. 2010, 12(3), 365-368.

(19) Feizi, H., Moghaddam, P. R., Shahtahmassebi, N., Fotovat, A. Impact of bulk and nanosized titanium dioxide $\left(\mathrm{TiO}_{2}\right)$ on wheat seed germination and seedling growth. Biol. Trace Elem. Res. 2012, 146(1), 101-106.

(20) Stampoulis, D., Sinha, S. K., White, J. C. Assay-dependent phytotoxicity of nanoparticles to plants. Environ. Sci. Technol. 2009, 43(24), 9473-9479.

(21) Dutta, P., Pal, S., Seehra, M. S., Shi, Y., Eyring, M., Ernst, R. D. Concentration of $\mathrm{Ce}^{3+}$ and oxygen vacancies in cerium oxide nanoparticles. Chem. Mater. 2006, 18, 5144-5146.

(22) Deshpande, S., Patil, S., Kuchibhatla, S. T., Seal, S. Size Dependency Variation in Lattice Parameter and Valency States in Nanocrystalline Cerium Oxide. Appl. Phys. Lett. 2005, 87(13), 133113

(23) Heckert, E. G., Karakoti, A. S., Seal, S., Self, W. T. The Role of Cerium Oxide 
State in the SOD Mimetic Activity of Nanoceria. Biomaterials. 2008, 29(18), 27052709.

470

471

472

473

474

475

476

477

478

479

480

481

482

483

484

485

486

487

488

489

490

491

492

493

494

495

496

497

498

500

501

502

(24) Lindberg, S., Strid, H. Aluminium Induces Rapid Changes in Cytoplasmic pH and Free Calcium and Potassium Concentrations in Root Protoplast of Wheat (Triticum aestivum). Physiol. Plantarum. 1997, 99(3), 405-414.

(25) Gomez-Garay, A., Pintos, B., Manzanera, J. A., Lobo, C., Villalobos, N., Martin, L. Uptake of $\mathrm{CeO} 2$ Nanoparticles and Its Effect on Growth of Medicago arborea in Vitro Plantlets. Biol. Trace. Elem. Res., 2014, 161, 143-150,

(26) Qu, C., Liu, C., Guo, F., Hu, C., Ze, Y., Li, C., Zhou, Q., Hong, F. Improvement of Cerium on Photosynthesis of Maize Seedlings Under a Combination of Potassium Deficiency and Salt Stress. Biol. Trace. Elem. Res., 2014, 155, 104-113.

(27) Qu, C., Gong, X., Liu, C., Hong, M., Wang, L., Hong, F. Effects of Manganese Deficiency and Added Cerium on Photochemical Efficiency of Maize Chloroplasts. Biol. Trace. Elem. Res., 2012, 146, 94-100.

(28) Wherrett, T., Ryan, P. R., Delhaize, E., Shabala, S. Effect of Aluminum on Membrane Potential and Ion Fluxes at the Apices of Wheat Roots. Funct. Plant Biol. 2005, 32(3), 199-208.

(29) Zaki, H. E. M., Takahata, Y., Yokoi, S. Analysis of the Morphological and Anatomical Characteristics of Roots in Three Radish (Raphanus sativus) Cultivars that Differ in Root Shape. J. Hortic. Sci. Biotech. 2012, 87(2), 172-178.

(30) Farrar, J. F. Regulation of Shoot-root Ratio is Mediated by Sucrose. Plant Soil. 1996, 185(1), 13-19.

(31) Rouhier, H.; Usuda, H. Spatial and Temporal Distribution of Sucrose Synthase in the Radish Hypocotyl in Relation to Thickening Growth. Plant cell physiol. 2001, 42(6), 583-593.

(32) Usuda, H.; Demura, T.; Shimogawara, K.; Fukuda, H. Development of Sink Capacity of the "Storage Root" in a Radish Cultivar with a High Ratio of "Storage Root" to Shoot. Plant Cell Physiol. 1999, 40(4), 369-377.

(33) Wardlaw, I. F. The Control and Pattern of Movement of Carbohydrates in Plants. Bot. Rev. 1968, 34(1), 79-105.

(34) Parida, A. K.; Das, A. B. Salt Tolerance and Salinity Effects on Plants: A Review. Ecotox. Environ. Safe. 2005, 60(3), 324-349.

(35) Scialabba, A.; Melati, M. R. The Effect of $\mathrm{NaCl}$ on Growth and Xylem Differentiation of Radish Seedlings. Bot. Gaz. 1990, 151(4), 516-521.

(36) Hu, X., Ding, Z., Chen, Y., Wang, X., Dai, L. Bioaccumulation of Lanthanum and 
503 Cerium and Their Effects on the Growth of Wheat (Triticum aestivum L.) Seedlings.

$504 \quad$ Chemosphere. 2002, 48(6), 621-629.

505

506

507

508

509

510

511

512

513

514

515

516

517

518

519

520

521

522

523

524

525

526

527

528

529

530

531

532

533

534

535

536

537

538

539

540

541

542

543

544

545

546

547 
548 Table 1: The relative chlorophyll content expressed as percentage of control of each 549 treatment, the average $\mathrm{Y}(\mathrm{II}), \mathrm{Fv}_{\mathrm{V}} / \mathrm{F}_{\mathrm{M}}$ ratio, $\mathrm{n}=12$. Different letters in the table represent 550 significant differences between the treatments $(\mathrm{p}<0.05)$.

551

\begin{tabular}{ccccccc}
\hline Treatment & $\begin{array}{c}\text { Relative } \\
\text { Chlorophyll (\%) }\end{array}$ & $\begin{array}{c}\text { Standard } \\
\text { error }\end{array}$ & Y(II) & $\begin{array}{c}\text { Standard } \\
\text { error }\end{array}$ & $\mathrm{FV}_{\mathrm{V}} \mathrm{F}_{\mathrm{M}}$ & $\begin{array}{c}\text { Standard } \\
\text { error }\end{array}$ \\
\hline \hline Control & $100.00^{\mathrm{a}}$ & 2.67 & 0.774 & 0.007 & $0.830^{\mathrm{a}}$ & 0.003 \\
Bulk & $87.22^{\mathrm{b}}$ & 3.84 & 0.728 & 0.022 & $0.757^{\mathrm{b}}$ & 0.026 \\
Nanoparticle & $83.69^{\mathrm{b}}$ & 4.24 & 0.731 & 0.020 & $0.780^{\mathrm{ab}}$ & 0.016 \\
Cerium ion & $91.51^{\mathrm{ab}}$ & 4.68 & 0.697 & 0.060 & $0.797^{\mathrm{ab}}$ & 0.020 \\
\hline
\end{tabular}

552

553

554

555

556

557

558

559

560

561

562

563

564

565

566

567

568

569

570

571

572

573

574

575

576

577

578

579

580

581

582

583

584

585

586

587 

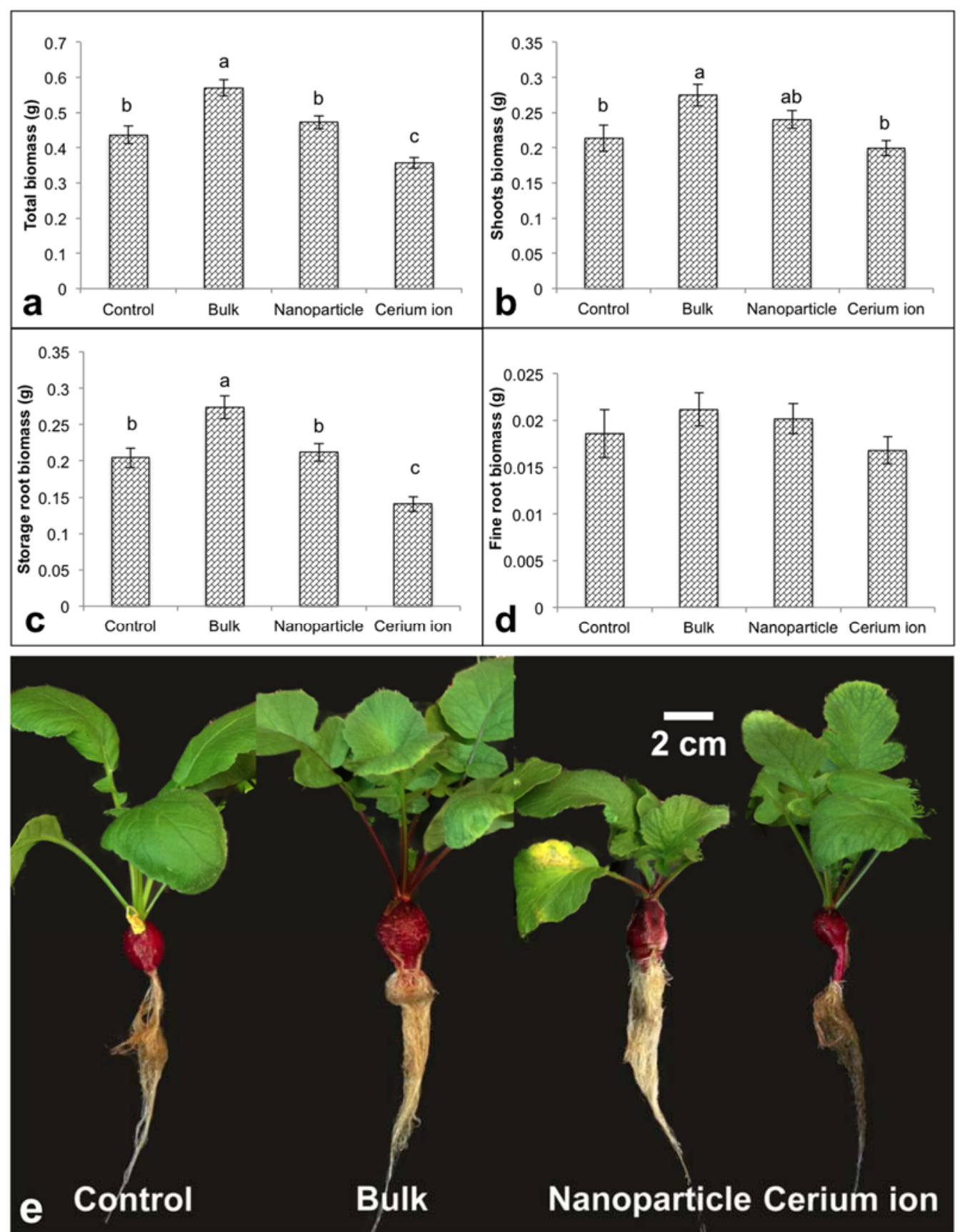

Figure 1: Dry biomass of total radish and different radish tissues treated with $10 \mathrm{mg} / \mathrm{L}$ of different forms of cerium (a-d). The reported values are the mean of 12 replicates and the error bars represent standard error. Different letters represent significant differences between the treatments $(\mathrm{p}<0.05)$. (e) Images of typical radish plants from the different

\section{4 treatments.}




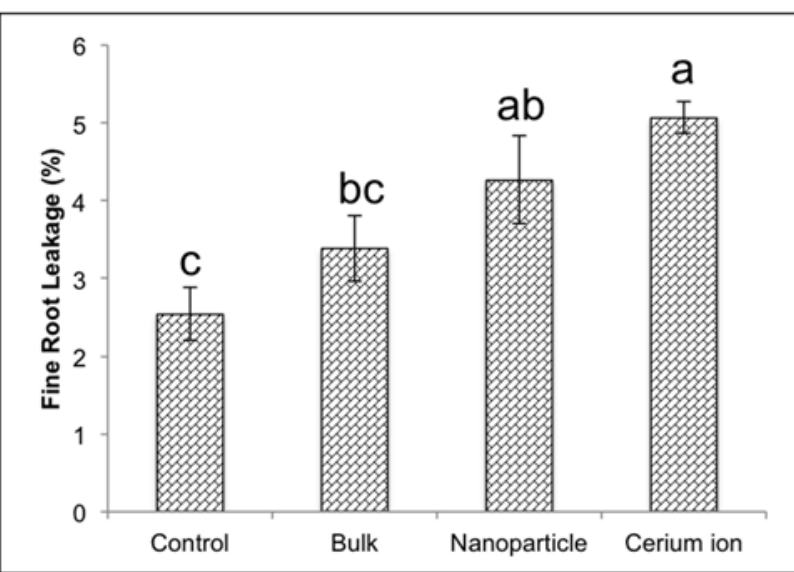

602

603 Figure 2: Electrolyte leakage from radish fine roots grown hydroponically in different 604 solutions. The reported values are the average of 5 replicates in each treatment and the 605 error bars represent standard error. Different letters represent significant differences 606 between the treatments $(\mathrm{p}<0.05)$.

607

608

609

610

611

612

613

614

615

616

617

618

619

620

621

622

623

624

625

626

627

628

629

630

631

632

633

634

635 

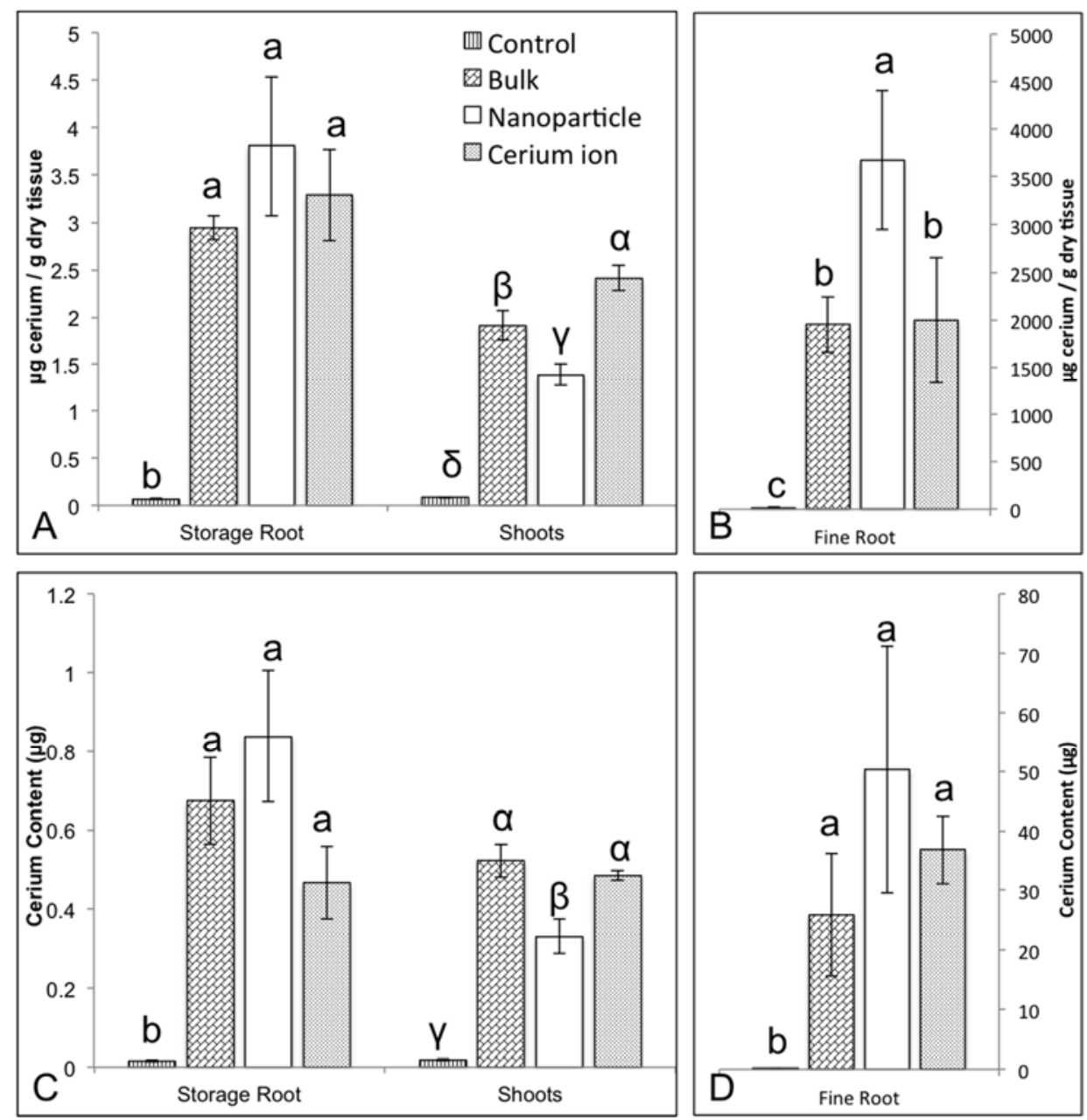

Figure 3: Cerium concentration ( $A$ and $B$ ) and mass ( $C$ and $D$ ) in different radish tissues. The reported values in $A$ and $C$ are the average of 4 measurements. The reported values in $\mathrm{B}$ and $\mathrm{D}$ are the average of 2 or 3 measurements. Errors bars represent standard error.

641 Letters above bars reflect their statistical grouping. Different letters and Greek symbols 642 represent significant differences between the treatments $(\mathrm{p}<0.05)$.

643

644

645

646

647

648

649

650 


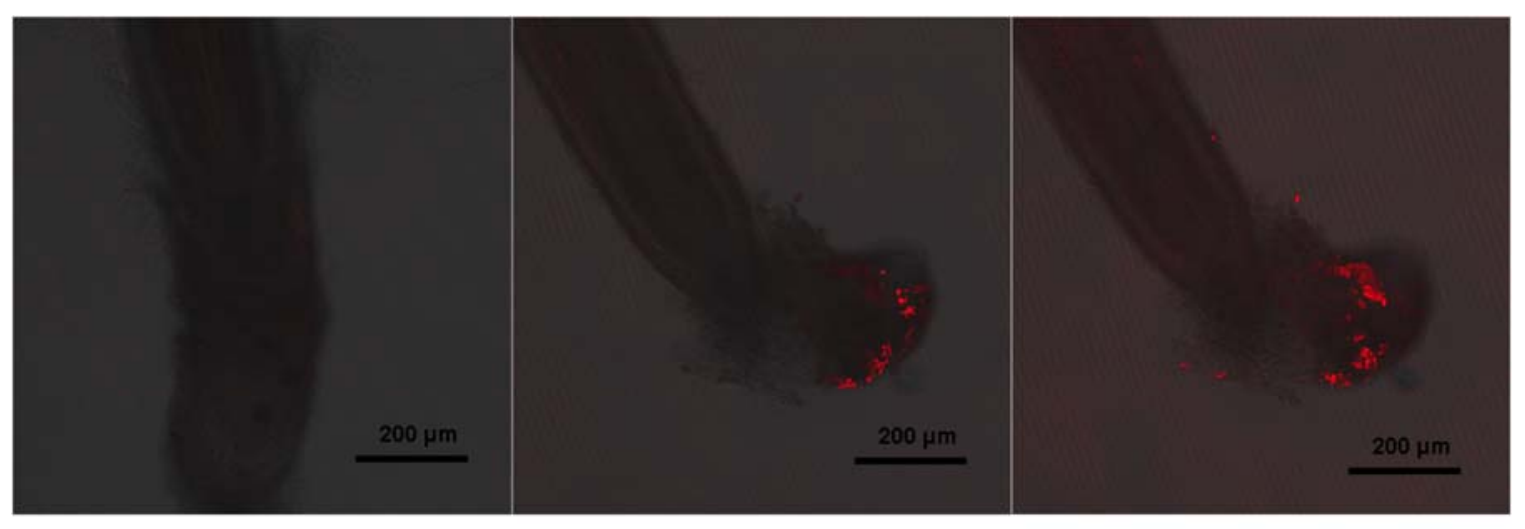
a. Control
b. Bulk (surface)
c. Bulk (deep scan)
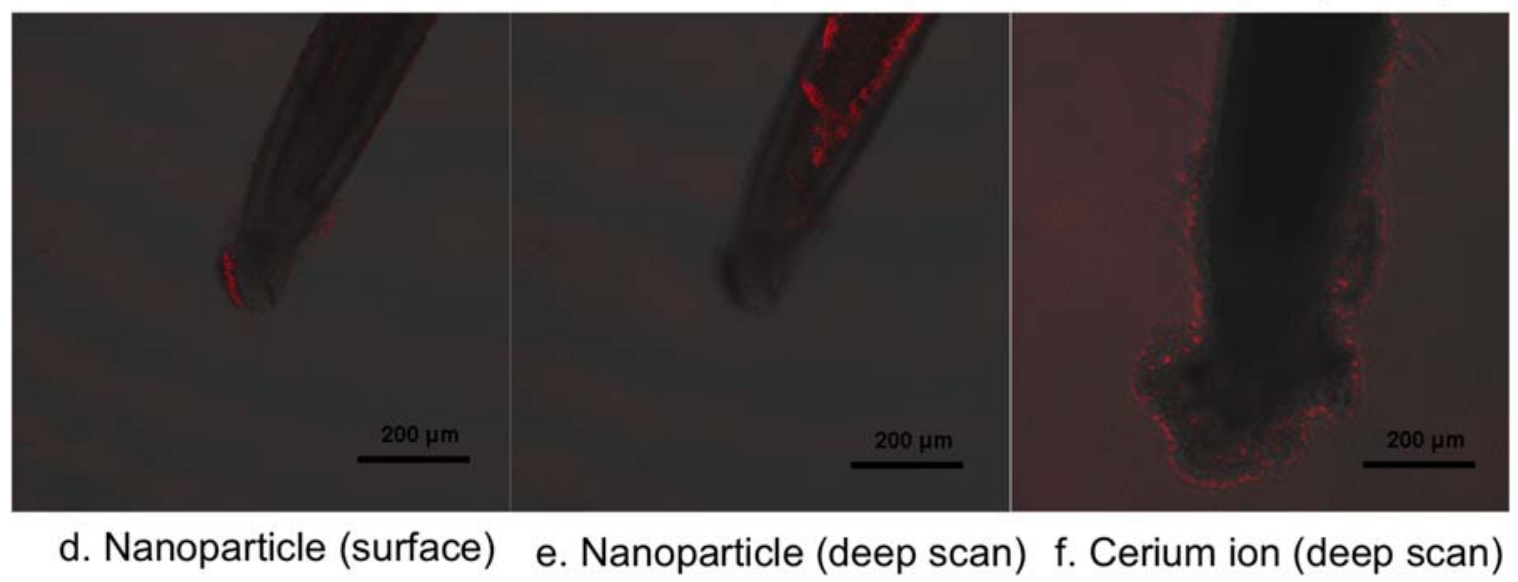

Figure 4: Confocal microscopic images depicting the accumulation of cerium in the fine roots of radish. (a) control root showing weak signals, (b, c) surface and representative 655 deeper scan of fine roots treated by bulk $\mathrm{CeO}_{2}$, $(\mathrm{d}, \mathrm{e})$ surface and representative deeper scan of fine roots exposed to $\mathrm{CeO}_{2} \mathrm{NPs}$ and (f) a deeper scan image of fine roots exposed to cerium ion. The deeper scan images shown were selected from a stack of deep scan images for different roots. 

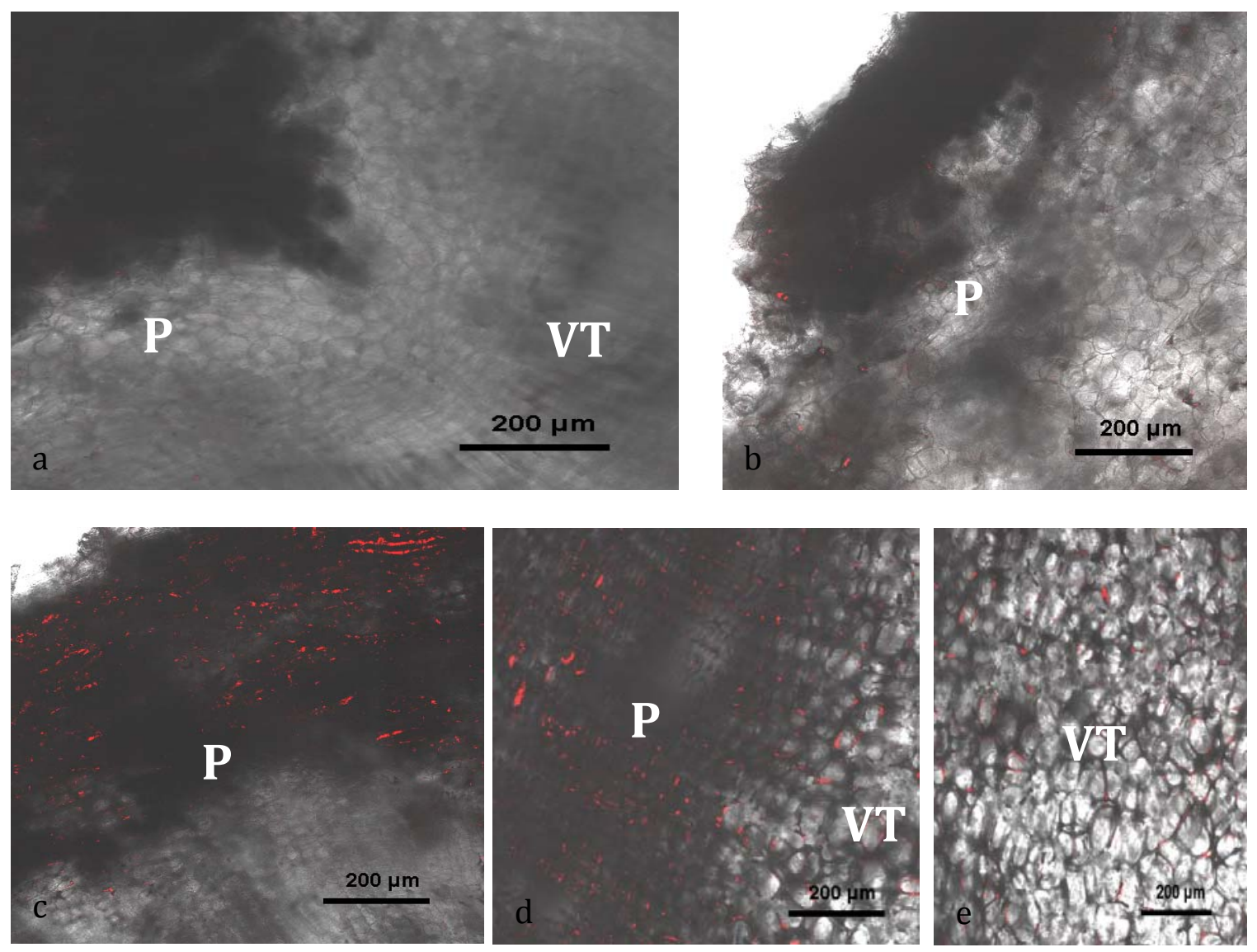

676

677

Figure 5: (a) Confocal images of the horizontal slices of radish storage root treated with

678 different types of cerium. (a): control; (b): bulk $\mathrm{CeO}_{2}$ treated radish; (c): $\mathrm{CeO}_{2} \mathrm{NPs}$

679 treated radish and (d, e): ionic cerium treated radish. P: Periderm; VT: Vascular tissues.

680

681

682

683

684

685

686

687

688

689

690

691

692

693

694

695

696 
TOC Graphic

699

700

701

702

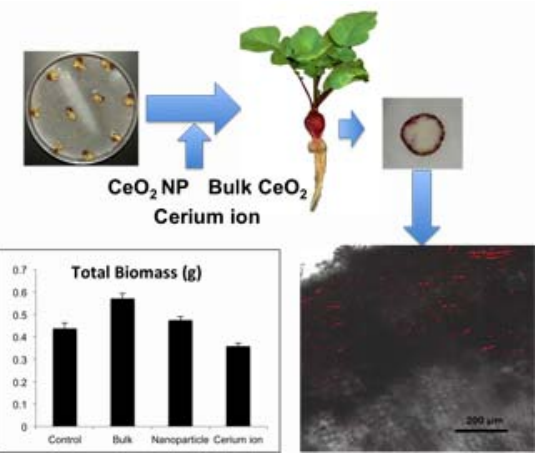

